\title{
BM]
}

\section{Selective serotonin reuptake inhibitors (SSRIs) and routine specialist care with and without cognitive behaviour therapy in adolescents with major depression: randomised controlled trial}

\begin{abstract}
Ian Goodyer, professor of child and adolescent psychiatry, ${ }^{1}$ Bernadka Dubicka, consultant in adolescent psychiatry and honorary lecturer, ${ }^{2}$ Paul Wilkinson, clinical lecturer in child and adolescent psychiatry, ${ }^{1}$ Raphael Kelvin, consultant child and adolescent psychiatrist and associate lecturer, ${ }^{3}$ Chris Roberts, senior lecturer in medical statistics, ${ }^{4}$ Sarah Byford, senior lecturer in health economics, ${ }^{5}$ Siobhan Breen, trainee, ${ }^{6}$ Claire Ford, health psychologist, ${ }^{7}$ Barbara Barrett, research worker, ${ }^{5}$ Alison Leech, consultant child and adolescent psychiatrist, ${ }^{8}$ Justine Rothwell, research associate, ${ }^{9}$ Lydia White, trial manager, ${ }^{10}$ Richard Harrington, former professor of child psychiatry ${ }^{11}$
\end{abstract}

DDevelopmental Psychiatry Section, Department of Psychiatry, Cambridge University, Cambridge CB2 2AH

Junction Adolescent Unit, Scotforth, Lancaster, and Department of Psychiatry, University of Manchester

${ }^{3}$ Brookside Family Consultation Centre, Cambridge, and Department of Psychiatry, University of Cambridge

${ }^{4}$ Biostatistics Group, Division of Epidemiology and Health

Sciences, Manchester University, Manchester

${ }^{5}$ Centre for the Economics of Mental Health, Institute of

Psychiatry, London

${ }^{6}$ Clinical Psychology Unit,

Department of Psychology,

Sheffield University, Sheffield

${ }^{7}$ Cambridgeshire Primary Care

Trust, Fulbourn, Cambridge

${ }^{8}$ Thorn Road Clinic, Halton,

Cheshire

${ }^{9}$ Division of Psychiatry, University of Manchester, Manchester

${ }^{10}$ Academic Department of Child and Adolescent Psychiatry, University of Manchester, Booth Hall Children's Hospital, Blackley, Manchester

${ }^{11}$ Department of Child and Adolescent Psychiatry, Manchester University, Royal Manchester Children's Hospital, Pendlebury, Manchester Correspondence to: I Goodyer ig104@cam.ac.uk

doi: 10.1136/bmj.39224.494340.55

\section{ABSTRACT}

Objective To determine whether a combination of a selective serotonin reuptake inhibitor (SSRIs) and cognitive behaviour therapy (CBT) together with clinical care is more effective in the short term than an SSRI and clinical care alone in adolescents with moderate to severe major depression.

Design Pragmatic randomised controlled superiority trial. Setting 6 outpatient clinics in Manchester and Cambridge.

Participants 208 adolescents, aged 11-17, with moderate to severe major or probable major depression who had not responded to a brief initial intervention. Adolescents with suicidality, depressive psychosis, or conduct disorder were included.

Interventions 103 adolescents received an SSRI and routine care; 105 received an SSRI, routine care, and CBT. The trial lasted 12 weeks, followed by a 16 week maintenance phase.

Main outcome measures Change in score on the Health of the Nation outcome scales for children and adolescents (primary outcome) from baseline with 12 weeks as the primary and 28 weeks as the follow-up end point. Secondary measures were change in scores on the mood and feelings questionnaire, the revised children's depression rating scale, the children's global assessment scale, and the clinical global impression improvement scale.

Results At 12 weeks the treatment effect for the primary outcome was -0.64 ( $95 \%$ confidence interval -2.54 to $1.26, \mathrm{P}=0.50$ ). In a longitudinal analysis, there was no difference in effectiveness of treatment for the primary (average treatment effect $0.001,-1.52$ to $1.52, \mathrm{P}=0.99$ ) or secondary outcome measures. On average there was a decrease in suicidal thoughts and self harm. There was no evidence of a protective effect of cognitive behaviour therapy on suicidal thinking or action. By 28 weeks, $57 \%$ were much or very much improved with $20 \%$ remaining unimproved.

Conclusions For adolescents with moderate to severe major depression there is no evidence that the combination of CBT plus an SSRI in the presence of routine clinical care contributes to an improved outcome by 28 weeks compared with the provision of routine clinical care plus an SSRI alone.

Trial registration Current Controlled Trials ISRCNT 83809224.

\section{INTRODUCTION}

Adolescent depression is a serious disorder with a high risk of suicidality, recurrence, and chronicity. ${ }^{12}$ Selective serotonin reuptake inhibitors (SSRIs) are used in treatment, although there are concerns regarding both efficacy and raised risk of suicide. ${ }^{34}$ The National Institute for Health and Clinical Excellence (NICE) has proposed cognitive behaviour therapy (CBT) as one of the primary treatments of choice. ${ }^{5}$ Specifically, their guidelines recommend that SSRIs are prescribed only in conjunction with a specialised psychological treatment such as CBT after results from the treatment of adolescent depression study (TADS) in the United States. ${ }^{6}$ The US randomised controlled trial showed that fluoxetine in combination with CBT was superior to fluoxetine alone and might reduce suicidality. Results of secondary analyses, however, were equivocal, and subsequent studies have reported no benefit for combined treatment over SSRIs alone. ${ }^{78}$

The US study has limited generalisability to depressed adolescents attending NHS child and adolescent mental health services (CAMHS) in the United Kingdom as it excluded adolescents with active suicidal intent, self harm, thought disorder, severe conduct 
disorder, and active substance misuse. Over half of the participants were recruited from advertisement, a method known to be associated with a better response to treatment. ${ }^{9}$ Similarly, most studies of SSRIs in young people have excluded active suicidality, a core feature of severe depression, thus reducing the applicability of the results to those treated in the NHS. ${ }^{4}$

The adolescent depression antidepressant and psychotherapy trial (ADAPT) was designed as a pragmatic randomised controlled superiority trial of combination therapy for moderate to severe major depression in routine patients referred to NHS child and adolescent mental health services. Meta-analytic review has shown that a quarter of depressed adolescents remit with brief psychosocial interventions ${ }^{10}$ and that studies should focus on combined treatments. We included only participants with persisting depression to test the hypothesis that in the presence of routine specialist clinical care, SSRI plus CBT would have a significantly better outcome by 12 or 28 weeks than treatment with an SSRI alone.

Initial clinical assessment $(n=510)$

\begin{tabular}{|c|c|}
\hline & $\begin{array}{l}\text { Excluded after initial assessment }(n=261) \text { : } \\
\text { Not depressed }(n=109) \\
\text { Did not attend }(n=48) \\
\text { Concerned about drugs }(n=39) \\
\text { Refused other reasons }(n=38) \\
\text { Ineligible other reasons }(n=20) \\
\text { Too ill }(n=6) \\
\text { Previous SSRI plus CBT }(n=1)\end{array}$ \\
\hline \multicolumn{2}{|c|}{ Considered for brief initial intervention $(n=249)$} \\
\hline \multicolumn{2}{|l|}{$\begin{array}{l}\text { Bypassed brief initial intervention }(n=85) \text { : } \\
\text { CAMHS clinical care already received }(n=34) \\
\text { Medication already commenced }(n=29) \\
\text { Medication urgently required }(n=22)\end{array}$} \\
\hline \multicolumn{2}{|c|}{ Eligible for and received brief initial intervention $(n=164)$} \\
\hline & $\begin{array}{l}\text { Excluded after receiving brief initial } \\
\text { intervention }(n=38) \text { : } \\
\text { Improved }(n=34) \\
\text { Refused }(n=4)\end{array}$ \\
\hline \multicolumn{2}{|c|}{ Did not respond to brief initial intervention $(n=126)$} \\
\hline$\downarrow$ & \\
\hline \multicolumn{2}{|c|}{ First research interview $(n=211)$} \\
\hline & $\begin{array}{l}\text { Excluded after first interview }(n=3) \text { : } \\
\rightarrow \quad \text { Refused }(n=2) \\
\\
\text { Improved }(n=1)\end{array}$ \\
\hline \multicolumn{2}{|c|}{ Randomised $(n=208)$} \\
\hline$\downarrow$ & $\downarrow$ \\
\hline $\begin{array}{l}\text { Randomised to SSRI alone }(n=103) \\
\text { Withdrew by } 12 \text { weeks }(n=6) \\
\text { Withdrew by } 28 \text { weeks }(n=7)\end{array}$ & $\begin{array}{l}\text { Randomised to SSRI plus CBT }(n=105) \\
\text { Withdrew by } 12 \text { weeks }(n=11) \\
\text { Withdrew by } 28 \text { weeks }(n=7)\end{array}$ \\
\hline$\downarrow$ & $\downarrow$ \\
\hline $\begin{array}{l}\text { Included in primary end point analysis at } \\
\text { week } 12(n=101) \\
\text { Refused final research assessment }(n=2)\end{array}$ & $\begin{array}{l}\text { Included in primary end point analysis at } \\
\text { week } 12(n=101) \\
\text { Refused final research assessment }(n=4)\end{array}$ \\
\hline
\end{tabular}

Fig 1| Recruitment and follow-up (SSRI=selective serotonin reuptake inhibitor, CBT=cognitive behaviour therapy)

\section{METHODS}

Protocol, design, and objectives

We used a pragmatic randomised superiority trial to determine whether, in those who did not respond to a brief initial intervention but were continuing to receive routine care, the addition of combined specialist therapy (SSRI plus CBT) was superior to the addition of an SSRI alone in improving general functioning and depression. After an initial assessment by trial psychiatrists, participants were offered a brief initial intervention based on principles of routine clinical care (see below) for a minimum of two sessions, if they had not had such a procedure before referral. We excluded those already taking antidepressants or those thought to require immediate treatment with antidepressants. If participants did not improve after the brief initial intervention, they were randomised to SSRI alone or SSRI plus CBT for 12 weeks, followed by a maintenance phase to 28 weeks.

\section{Participants}

Adolescents were recruited from six specialist CAMHS services in Manchester and Cambridge. All participants met criteria for major or probable major depression (four symptoms with psychosocial impairment $)^{11}$ consistent with a previous randomised controlled trial. ${ }^{9}$ We included participants aged 11-17, of either sex, and with a score of 7 or more on the Health of the Nation outcome scales for children and adolescents, indicating moderate to severe difficulties. ${ }^{12}$ Patients with active suicidal intent, self harm, depressive psychosis, or conduct disorder were included. All participants were recruited between autumn 2000 and autumn 2004.

Our exclusion criteria were schizophrenia or bipolar disorder; need for immediate admission; pregnancy or unreliable use of contraception; global learning disability (formal testing not undertaken); prior sensitivity or allergy to an SSRI; medication that could interact with an SSRI; medical contraindication; and previous combined optimal treatment with an SSRI and CBT with no effect.

\section{Assignment}

Participants were randomised to SSRI alone or SSRI plus CBT by an equal allocation ratio using stochastic minimisation balancing for severity (children's global assessment scale $\leq 40$ ), centre, sex, concurrent comorbid conduct disorder, and age. Research staff from the clinical sites enrolled patients, and an independent telephone randomisation centre allocated treatment.

\section{Interventions}

Treatments reflected real life best practice. Treatment manuals for both treatment arms were used to standardise the intervention between therapists, and treatment adherence was determined from audiotapes. As this was a pragmatic study, manuals were guides and principles of treatment that could be incorporated into normal practice. Trial psychiatrists treated participants in 
outpatient settings in the context of ongoing clinical care. Treatment was conducted in an empathic and reflective framework with monitoring of mental state, psychoeducation, parental support, problem solving, attention to comorbidity, and liaison with other agencies. Family therapy was kept to a minimum (up to three sessions) in the first 12 weeks. The focus of usual care was an explanation of depression and attention to recent family or peer group conflicts. Comorbidity problems were also attended to when required, including liaison with schools and other agencies.

Drug treatment-The primary SSRI was fluoxetine $10 \mathrm{mg}$ daily for one week, increasing to $20 \mathrm{mg}$ for five weeks. If there was no response by six weeks, a further increase was considered ( $40 \mathrm{mg}$ on alternate days for one week followed by $40 \mathrm{mg}$ daily for five weeks). If participants did not respond by 12 weeks, the dose could be increased to $60 \mathrm{mg}$ on alternate days for a week followed by $60 \mathrm{mg}$ daily for five weeks. If fluoxetine was ineffective or caused side effects, other SSRIs were considered. Patients who were taking a different

Table 1 | Characteristic of adolescents with depression according to allocated treatment with selective serotonin reuptake inhibitors (SSRIs) alone or in combination with cognitive behaviour therapy (CBT). Figures are numbers (percentages) of patients unless stated otherwise

\begin{tabular}{|c|c|c|}
\hline & SSRI $(n=103)$ & $\begin{array}{l}\text { CBT plus SSRI } \\
(\mathrm{n}=105)\end{array}$ \\
\hline Female & $75(73)$ & $79(75)$ \\
\hline Median (range) age (years) & $14(11-17)$ & $14(11-17)$ \\
\hline \multicolumn{3}{|l|}{ Study centre: } \\
\hline Manchester & $74(72)$ & $75(71)$ \\
\hline Cambridge & $29(28)$ & $30(29)$ \\
\hline Behavioural disorder & $30(29)$ & $33(31)$ \\
\hline CGAS $>40$ & $58(56)$ & $49(47)$ \\
\hline Mean (SD) depressive symptoms & $6.6(1.5)$ & $6.4(1.4)$ \\
\hline \multicolumn{3}{|l|}{ Comorbid diagnosis: } \\
\hline Social phobia & $49(48)$ & $43(41)$ \\
\hline Obsessive compulsive disorder & $37(36)$ & $42(40)$ \\
\hline Post-traumatic stress disorder & $36(35)$ & $42(40)$ \\
\hline Agoraphobia & $29(28)$ & $36(34)$ \\
\hline Separation anxiety disorder & $28(27)$ & $31(29)$ \\
\hline Specific phobia & $22(22)$ & $25(26)$ \\
\hline Conduct disorder & $17(17)$ & $18(17)$ \\
\hline Panic disorder (without agoraphobia) & 14 (14) & $21(20)$ \\
\hline Oppositional defiance disorder & $13(13)$ & $17(16)$ \\
\hline Generalised anxiety disorder & $13(13)$ & $19(18)$ \\
\hline Panic disorder (with agoraphobia) & $13(13)$ & 20 (19) \\
\hline ADHD & $6(6)$ & $5(5)$ \\
\hline Bulimia nervosa & $4(4)$ & $8(8)$ \\
\hline Alcohol abuse & $4(4)$ & $1(1)$ \\
\hline Transient tic disorder & $3(3)$ & $2(2)$ \\
\hline Tourette's syndrome & $2(2)$ & $2(2)$ \\
\hline Alcohol dependence & $2(2)$ & $1(1)$ \\
\hline Chronic motor or vocal tic disorder & $1(1)$ & $2(2)$ \\
\hline Anorexia nervosa & 0 & $1(1)$ \\
\hline Encopresis & 0 & $1(1)$ \\
\hline Enuresis & 0 & $1(1)$ \\
\hline Dysthymia & 0 & $1(1)$ \\
\hline
\end{tabular}

CGAS=children's global assessment scale; $A D H D=$ attention deficit hyperactivity disorder.
SSRI at randomisation continued with their prescription, but if it was ineffective, the dose was increased or fluoxetine was used instead. Patients in the SSRI only arm were offered nine outpatient sessions of usual care as described above over 28 weeks; more could be offered depending on clinical need.

Therapy-CBT was offered weekly for 12 weeks, then fortnightly for 12 weeks with a final session at 28 weeks (total 19 sessions). Intensive efforts were made to ensure participants continued in therapy if they missed appointments - for example, they were contacted by telephone, offered further appointments, and had taxi fares refunded if transport was a problem. Four psychiatrists provided CBT to 75 participants. One was a CBT supervisor $(\mathrm{RCH})$; the others had previous CBT training (two trainees in child psychiatry (AL and PW); one after training (BD)) and attended a three day training course on CBT for depression. Before the study they all had to deliver supervised CBT to at least three patients to an agreed level of competence. In addition, 30 participants were treated by 10 CBT therapists (mostly psychologists). There was a focus on depressive symptoms early in treatment, but comorbidity was also addressed. Core interventions were engagement and goal setting, emotional recognition, self monitoring, self reinforcement and activity scheduling, challenging negative thinking and cognitive restructuring, social problem solving, and communication skills. When required, therapy could include more overt behavioural strategies establishing hierarchies, exposure, and reward techniques. Parental participation at the end of each session was encouraged. CBT was supervised by accredited CBT supervisors. Audiotapes of CBT sessions were rated with a modified version of the cognitive therapy scale ${ }^{13}$ (inter-rater reliability, $\kappa=0.8)$. Compliance with medication and CBT was rated on a Likert scale at each session from 1 (none) to 8 (full). Participants were asked to bring medication containers to sessions.

\section{Outcomes}

All assessment measures were given at baseline, 6, 12, and 28 weeks. The Kiddie Schedule for affective disorders and schizophrenia present and lifetime version (K-SADS-PL) ${ }^{14}$ established the presence of diagnoses for depression and all concurrent comorbid psychiatric disorders (inter-rater diagnostic agreement $\kappa$ for depression 0.71-0.91). The Health of the Nation outcome scale was the primary outcome measure ${ }^{12}$ with 12 weeks as the primary and 28 weeks as the follow-up end point. The scale is interviewer rated, assesses global impairment, and is sensitive to change. ${ }^{15}$ The interrater reliability (intraclass correlation coefficient) was 0.89-0.94. Secondary measures were the participant rated mood and feelings questionnaire ${ }^{16}$ the observer rated revised children's depression rating scale (CDRS-R, reporting the (t) score), ${ }^{17}$ the children's global assessment scale (CGAS) ${ }^{18}$ and the clinical global impression improvement scale (CGI-I), ${ }^{19}$ scores being obtained from combining participants' and parents' reports. We used the suicidality items from the 


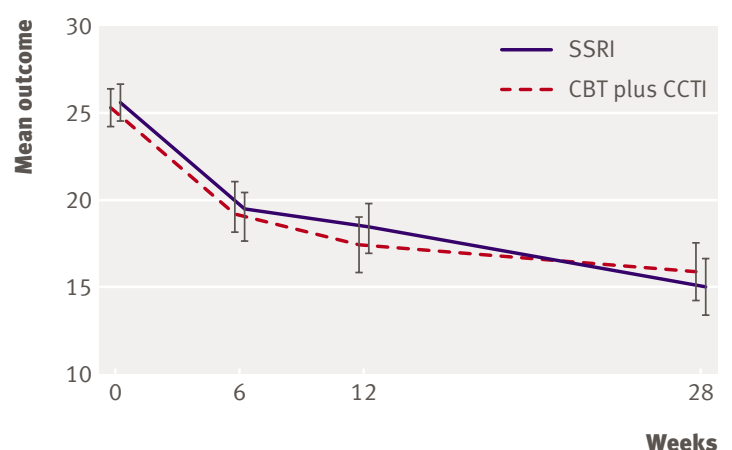

Fig 2 | Mean outcome by treatment group (95\% confidence interval) for the Health of the Nation outcome scale (SSRI=selective serotonin reuptake inhibitor, CBT=cognitive behaviour therapy)

K-SADS-PL depression section as a secondary measure to rate suicidality at each research assessment. These included all acts of self harm, including attempted suicide and non-suicidal self cutting, as well as suicidal thoughts.

Treating clinicians could not be blind to treatment; research assistants blind to treatment assignment assessed outcome.

\section{Sample size}

We used the outcome score to determine sample size. Data from the development study ${ }^{12}$ and the overdose study ${ }^{20}$ suggested that 3 points on the total score scale was a clinically important difference. With a sample size of 100 in each arm we would have $94 \%$ power to detect a difference of this magnitude with a two tailed 0.05 significance level, assuming a common SD of 6.0 points.

\section{Statistical analysis}

Analysis was by intention to treat subject to the availability of the data. For each outcome measure we used a random effects model to compare the two treatments in a longitudinal analysis. ${ }^{21}$ As well as treatment group, we included baseline value of the outcome measure and comorbid diagnoses (treated as two groups, behavioural and anxiety disorders), clinical centre (Manchester or Cambridge), time from randomisation, and variables used in minimisation as covariates.

We used statistical models ${ }^{21}$ to estimate the difference in the rate of improvement between the two treatments using a time-treatment interaction. The "average treatment effect" reported refers to the mean differences in the outcome averaged across follow-up time points $(6,12$, and 28 weeks). To account for possible therapist effects we added a random intercept term to the CBT plus SSRI treatment arm of the model. ${ }^{2223}$ We analysed the clinical global impression improvement scale, a 7 point scale, with an ordinal logistic regression model. The effect of treatment on suicidal and self harm behaviour was analysed with the proportion of patients rated at clinical threshold levels in a logistic model. We used the xtmixed and gllamm procedures in STATA release 9 for analyses.

\section{RESULTS}

\section{Participants}

From 2000 to 2004, 510 patients were assessed, of whom 249 (49\%) met inclusion criteria (fig 1).

Overall, $164(65 \%)$ received a brief initial intervention; 34 (21\%) subsequently improved and were withdrawn. Eighty five participants did not undergo the brief initial intervention: 34 with non-remitting depression had already received a psychosocial intervention for depression before referral to the trial team; 22 had particularly severe depression (children's global assessment scale $<40$, reflecting major impairment in functioning) and entered the trial as soon as possible for clinical safety reasons; and 29 were already taking an antidepressant. Our participants were considerably impaired and suicidal and many of those included in this trial would have been excluded from other trials of depression. ${ }^{679}$ Most participants had already been treated and would have received psychosocial interventions before medication. Of 211 available for first research interview, three dropped out, 103 were randomised to SSRI alone, and 105 were randomised to CBT plus SSRI. Table 1 shows characteristics of the participants. Twelve patients were formally withdrawn from the study for clinical reasons: four required admission for suicidality or self harm, five failed to improve, one had a fit and one had an allergic reaction, which were possibly secondary to medication; and one was prescribed paroxetine by a general practitioner. Families of 18 patients formally withdrew them from study treatment: six were improved or improving and didn't want further treatment; five did not want more treatment; two wanted CBT; two did not want CBT; one wanted a female therapist; one was getting worse; and one moved.

\section{Medication}

The mean dose of fluoxetine was $30 \mathrm{mg}$ for both groups. Two patients received the maximum dose of $60 \mathrm{mg}$. Of those randomised, 26 were taking other SSRIs on entry to the trial and three switched to fluoxetine. Eleven changed from fluoxetine to another SSRI. Compliance with medication was measured on a Likert scale of 1-8, with 8 representing total compliance: $160(77 \%)$ participants had a median score greater than 6 , with no difference between arms $(\mathrm{P}=0.83)$. Over the course of the trial 14 patients received additional psychotropic medication (atypical antipsychotics in five, methylphenidate in four, clonidine in one, a mood stabiliser in two, and hypnotics in two).

\section{Attendance}

Compared with SSRI alone, at 28 weeks the mean number of clinical sessions attended was significantly greater in the SSRI plus CBT arm (6.5 (SD 4.0) v 10.6 (SD 5.7); Mann-Whitney, $\mathrm{P}<0.0001)$. Typical durations of clinical trial sessions were 30 (SSRI alone) and 55 (CBT plus SSRI) minutes. The number of 
outpatient attendances was significantly higher in Cambridge $(\mathrm{n}=59)$ than in Manchester $(\mathrm{n}=149)$ by 28 weeks (11.7 (SD 4.9) v 7.4 (SD 5.1) sessions, Mann-Whitney, $\mathrm{P}<0.0001)$. A total of $32(15 \%)$ participants (14 in SSRI group, 18 CBT plus SSRI group) withdrew before the end of the study.

\section{Quality of CBT}

Quality of CBT was rated on $86(82 \%)$ cases. The mean score was 57.1 (SD 10.9). Scores above the midpoint (39) of the CBT scale ${ }^{13}$ equals acceptable quality.

\section{Clinical outcomes}

We had data at one or more assessment points over the 28 weeks for $204(98 \%)$ patients. Primary endpoint data were available for 202/208 (97\%) at 12 weeks and 193/ $208(93 \%)$ at 28 weeks. Table 2 shows the summary statistics for the primary and secondary outcome measures. Figure 2 displays the profile of the unadjusted means for the Health of the Nation outcome scale.

Mean values for the two treatments were similar at corresponding assessments. At the primary end point (12 weeks) the treatment effect for the primary outcome was $-0.64(95 \%$ confidence interval -2.54 to $1.26, \mathrm{P}=0.50$ ) after adjustment for age, sex, site, behavioural disorder, and baseline score. In the random effects model (table 2) there were no differences in either the time-treatment interaction or the average treatment effect of the follow-up time points. For the Health of the Nation outcome scale, the treatment effect (between groups) averaged across follow-up time points was $0.001(-1.52$ to $1.52, \mathrm{P}=0.99)$. There was no evidence of an interaction between treatment and baseline severity for primary (interaction 0.78 ; -2.38 to $3.92, \mathrm{P}=0.63$ ) or any secondary outcome (children's depression rating scale-revised (reporting the $(\mathrm{t}$ ) score) $\mathrm{P}=0.37$, mood and feelings questionnaire $\mathrm{P}=0.37$, children's global assessment scale $\mathrm{P}=0.44$ ).

The correlation coefficients within therapists (proportion of the variance caused by the therapist) calculated from the restricted maximum likelihood procedure, estimated variance components were small for all measures (Health of the Nation outcome scale 0.017 , children's depression rating scale $(\mathrm{t}) 0.005$, mood and feelings questionnaire 0.005 and children's global assessment scale $=0.033$ ).

For the clinical global impression improvement scale the proportion of patients in each category was similar between treatment arms (table 3).

By 28 weeks 57/94 (61\%) of those in the SSRI alone group and 52/98 (53\%) of the CBT plus SSRI group were much or very much improved; 16/94 (17\%) of those in the SSRI alone group and 24/98 (25\%) of those in the CBT plus SSRI group reported no response or worsening of symptoms. In the ordinal logistic random effects analysis there was no evidence of a difference between the two treatments: the common odds ratio for the average treatment effect of a higher score for CBT plus SSRI compared with SSRI alone was 1.28 (0.81 to $2.01, \mathrm{P}=0.30)$.

Table 2 | Comparison of groups for primary and secondary outcome measures according to allocated treatment with selective serotonin reuptake inhibitors (SSRIs) alone or in combination with cognitive behaviour therapy (CBT)

\begin{tabular}{|c|c|c|c|c|c|c|}
\hline \multirow[b]{2}{*}{ Outcome } & \multicolumn{2}{|c|}{ SSRI } & \multicolumn{2}{|c|}{ CBT plus SSRI } & \multirow{2}{*}{$\begin{array}{l}\text { Time-treatment interaction* } \\
(95 \% \mathrm{Cl}) ; \mathrm{P} \text { value }\end{array}$} & \multirow{2}{*}{$\begin{array}{l}\text { Treatment effect* } † \\
(95 \% \mathrm{Cl}) ; \mathrm{P} \text { value }\end{array}$} \\
\hline & Mean (SD) & No of patients & Mean (SD) & No of patients & & \\
\hline \multicolumn{7}{|l|}{ Primary } \\
\hline \multicolumn{7}{|c|}{ Health of the Nation outcome scales for children and adolescents: } \\
\hline Base & $25.5(5.6)$ & 103 & $25.1(5.5)$ & 105 & \multirow{4}{*}{$0.048(-0.059$ to 0.155$) ; 0.38$} & \multirow{4}{*}{$0.001(-1.519$ to 1.521$) ; 1.00$} \\
\hline 6 weeks & $19.2(7.6)$ & 98 & $18.7(7.0)$ & 98 & & \\
\hline 12 weeks & $18(7.5)$ & 101 & $17.1(8.3)$ & 101 & & \\
\hline 28 weeks & $14.5(8.3)$ & 95 & $15.4(8.6)$ & 98 & & \\
\hline \multicolumn{7}{|l|}{ Secondary } \\
\hline \multicolumn{7}{|c|}{ Children's depression rating scale-revised (t score): } \\
\hline Base & $75.3(6.7)$ & 103 & $75.1(6.7)$ & 105 & \multirow{4}{*}{$-0.023(-0.189$ to 0.143$) ; 0.79$} & \multirow{4}{*}{$1.432(-0.709$ to 3.572$) ; 0.19$} \\
\hline 6 weeks & $64.6(10.1)$ & 97 & $65.3(9.3)$ & 98 & & \\
\hline 12 weeks & $61(11.8)$ & 99 & $62.8(12.4)$ & 100 & & \\
\hline 28 weeks & $55.8(12.7)$ & 94 & $57.3(13.5)$ & 98 & & \\
\hline \multicolumn{7}{|c|}{ Mood and feelings questionnaire: } \\
\hline Base & $38.2(12.7)$ & 103 & 37.9 (11.9) & 105 & \multirow{4}{*}{0.087 ( -0.108 to 0.287$) ; 0.37$} & \multirow{4}{*}{1.271 ( -1.256 to 3.797$) ; 0.32$} \\
\hline 6 weeks & $25.4(13.8)$ & 97 & $25.5(13.0)$ & 98 & & \\
\hline 12 weeks & $21.6(14.8)$ & 99 & $22.7(15.4)$ & 100 & & \\
\hline 28 weeks & $15.5(15.0)$ & 93 & $18.9(15.5)$ & 98 & & \\
\hline \multicolumn{7}{|c|}{ Children's global assessment scale: } \\
\hline Base & $40.3(6.3)$ & 103 & $41.6(6.0)$ & 105 & \multirow{4}{*}{$-0.029(-0.218$ to 0.160$) ; 0.76$} & \multirow{4}{*}{$0.162(-2.535$ to 2.860$) ; 0.91$} \\
\hline 6 weeks & $48(10.2)$ & 98 & $48.9(10.7)$ & 98 & & \\
\hline 12 weeks & $50.7(12.1)$ & 100 & $52.1(14.3)$ & 101 & & \\
\hline 28 weeks & $57.8(14.5)$ & 94 & $57.2(16.4)$ & 98 & & \\
\hline
\end{tabular}

*Adjusted for time, sex, age, site, behavioural disorder, and baseline value of outcome measure.

tRefers to estimated mean across three follow-up time points. 


\section{Suicidality and self harm}

Symptoms of suicidality and self harm reduced over time for both treatments for most outcomes so that the odds reduced over time (table 4). For non-suicidal self harm there was evidence of a time-treatment interaction $(\mathrm{P}=0.070)$ and a mean treatment effect across follow-up time points $(\mathrm{P}=0.023)$. This was probably because few participants in the SSRI alone group reported threshold levels of self harm at the six week assessment. When we removed this time point from the longitudinal analysis the interaction $(\mathrm{P}=0.57)$ and mean treatment effect $(\mathrm{P}=0.24)$ were no longer present.

\section{Adverse events}

Some 59\% (61/103) in the SSRI alone group and 62\% $(65 / 105)$ in the CBT plus SSRI group reported side effects (adjusted odds ratio $1.05,0.58$ to 1.91 , $\mathrm{P}=0.87$ ). In one participant this was severe (one fit possibly related to medication in the SSRI alone group). The commonest reported adverse events or side effects were headaches, nausea, tiredness, dry mouth, and

\begin{abstract}
Table 3 | Ordinal logistic random effects model analysis* for clinical global impression improvement scale (CGI). Figures are numbers of patients according to allocated treatment with selective serotonin reuptake inhibitors (SSRIs) alone or in combination with cognitive behaviour therapy (CBT)
\end{abstract}

\begin{tabular}{|c|c|c|}
\hline & SSRI & CBT plus SSRI \\
\hline \multicolumn{3}{|l|}{ At 6 weeks } \\
\hline Very much improved & 3 & 1 \\
\hline Much improved & $32(33)$ & 33 \\
\hline Minimally improved & $36(37)$ & 37 \\
\hline No change & $16(16)$ & 16 \\
\hline Minimally worse & $8(8)$ & $6(6)$ \\
\hline Much worse & $2(2)$ & $2(2)$ \\
\hline Very much worse & $1(1)$ & $2(2)$ \\
\hline No of patients & 98 & 97 \\
\hline \multicolumn{3}{|l|}{ At 12 weeks } \\
\hline Very much improved & $12(12)$ & $5(5)$ \\
\hline Much improved & $32(32)$ & $37(36.6)$ \\
\hline Minimally improved & $27(27)$ & $29(28.7)$ \\
\hline No change & $7(7.0)$ & $9(8.9)$ \\
\hline Minimally worse & $11(11)$ & $10(9.9)$ \\
\hline Much worse & $8(8)$ & $4(4.0)$ \\
\hline Very much worse & $4(4)$ & $7(6.9)$ \\
\hline No of patients & 101 & 101 \\
\hline \multicolumn{3}{|l|}{ At 28 weeks } \\
\hline Very much improved & $20(21.3)$ & $19(19.4)$ \\
\hline Much improved & $37(39.4)$ & $33(33.7)$ \\
\hline Minimally improved & $21(22.3)$ & $22(22.4)$ \\
\hline No change & $6(6.4)$ & $11(11.2)$ \\
\hline Minimally worse & $3(3.2)$ & $7(7.1)$ \\
\hline Much worse & $3(3.2)$ & $3(3.1)$ \\
\hline Very much worse & $4(4.3)$ & $3(3.1)$ \\
\hline No of patients & 94 & 98 \\
\hline
\end{tabular}

*Odds ratio (adjusted for sex, age, behaviour disorder, site, and baseline Health of the Nation outcome scales for children and adolescents, children's depression rating scale (T), mood and feelings questionnaire, and children's global assessment scale) $1.01,95 \% \mathrm{Cl} 0.97$ to 1.05 , Wald $\mathrm{P}=0.67$, for time-treatment interaction and $1.28,0.81$ to $2.01, P=0.29$, for average treatment effect (estimated mean across the three follow-up time points). Odds ratios $>1$ indicate worse outcome for CBT plus SSRI than SSRI. reduced appetite. Irritability was reported in $4 \%$ $(8 / 208)$ and disinhibition in less than $1 \%(1 / 208)$.

\section{DISCUSSION}

\section{Principal findings}

In these adolescents in routine specialist clinic care with moderate to severe depression the addition of cognitive behaviour therapy to treatment with an SSRI had no benefit over treatment with an SSRI alone. Around one in five patients improved with a brief psychosocial intervention, consistent with previous reports. ${ }^{910}$ Eighty six $(43 \%)$ by 12 weeks and $109(57 \%)$ by 28 weeks reported being much or very much improved, indicating an increasing proportion of patients showing recovery by the secondary end point. These findings are consistent with those of one recent trial that tested the effects of combined treatment against SSRIs alone ${ }^{7}$ but differed from the results of the US treatment of adolescent depression study, which showed combined treatment to be more effective than fluoxetine alone on some but not all of their outcome measures. This was true only for patients with moderate but not severe depression. ${ }^{624}$ In our study neither severity nor comorbidity influenced the results and SSRI plus CBT was no more effective in relatively milder cases, bearing in mind that our participants were probably the most severely impaired in any randomised controlled trial to date. ${ }^{679}$ Importantly, we did not exclude any cases on the basis of suicidality.

The US study suggested that compared with fluoxetine alone, combined treatment with CBT was protective against suicidality. ${ }^{6} \mathrm{We}$ found no evidence to support this, nor did we find an increase in suicidality associated with SSRI use, though our study was not powered to detect such a difference. Overall all forms of suicidal thoughts and actions and self harm reduced over the study period.

By the assessment at 28 weeks there were $40(21 \%)$ non-responders (rated no change through to very much worse) across both treatment arms, comparable with prior research. ${ }^{9}$

\section{Strengths and weaknesses}

Our participants were typical of adolescents with major depression in the NHS and included those with severe illness with considerable impairment, active suicidality, and self harm. In addition, we excluded adolescents who responded to the brief initial intervention, ensuring that we randomised only those with persistent depression. The US study also found no greater response to combined treatment than to fluoxetine alone in their subgroup of more severely affected patients. ${ }^{24}$ Taken with the current findings this implies that psychiatrists who treat adolescents should consider prescribing fluoxetine in severe cases characterised at diagnosis by greater than eight symptoms, suicidal ideas, self harm, or psychotic thoughts.

One weakness is the absence of a placebo arm, which we considered to be unethical in such ill patients, so we cannot draw any conclusions regarding overall effectiveness of treatment. The response rates in both arms, 
however, are consistent with those of active treatments in trials that incorporated a control condition, ${ }^{69}$ suggesting that the treatments were similarly effective. The lack of a CBT alone group prevents direct comparisons between SSRI and CBT. When we were designing the trial, however, 48 child psychiatrists surveyed considered the treatments chosen as the most appropriate for severe depression. Subsequent evidence has shown that in non-suicidal populations CBT alone did not differentiate from placebo and was a significantly poorer treatment than SSRI alone. ${ }^{6}$ Therapists, participants, and their families may have expected a greater response in the CBT plus SSRI arm, but if such a bias was operating it seems insufficient to influence the results in favour of this group.

Low attendance rates for CBT may have reduced response, despite the intensive efforts made to maintain therapeutic contact. This reflects the clinical realities of implementing treatment for severely depressed adolescents attending NHS outpatient services. Whether the use of fully trained CBT therapists together with more sessions and longer treatment duration would influence rate of response is unclear and deserves further investigation. Although ratings of audiotaped sessions showed that trained CBT therapists delivered somewhat better treatment in this study than those who delivered CBT under supervision, this did not result in improved outcome. Active specialist clinical care delivered in both arms may have been of a higher quality than general family support and contained more psychologically effective components than would be found in routine care delivered in most hard pressed NHS clinics. If this were true for the active clinical care in this study it might have reduced treatment effects of adding CBT. The US findings showed that CBT without active clinical care was no better than placebo, which supports the lack of added effect of CBT in our study. Our study was powered to detect only superiority of one treatment over the other, and not equivalence, so although there is no difference in outcome we can not say there is evidence that treatments are equally effective. In addition there was insufficient power to detect differences in suicidality and self harm between the treatment arms. We examined only short term effects of treatment and longer term outcomes should be used in future studies.

\section{Policy implications}

Current guidelines from the National Institute for Health and Clinical Excellence (NICE) recommend that SSRIs should be given only to moderate to severely depressed adolescents in combination with a

Table 4 | Proportion of patients with clinical symptoms of suicidality and self harm by treatment group and assessment according to allocated treatment with selective serotonin reuptake inhibitors (SSRIs) alone or in combination with cognitive behaviour therapy (CBT)

\begin{tabular}{|c|c|c|c|c|c|c|}
\hline & \multicolumn{2}{|c|}{ SSRI } & \multicolumn{2}{|c|}{ CBT plus SSRI } & \multirow{2}{*}{$\begin{array}{l}\text { Time-treatment interaction* } \\
\quad(95 \% \mathrm{Cl}) ; \mathrm{P} \text { value }\end{array}$} & \multirow{2}{*}{$\begin{array}{l}\text { Treatment effect }{ }^{\star} \dagger \\
(95 \% \mathrm{Cl}) ; \mathrm{P} \text { value }\end{array}$} \\
\hline & Frequency (\%) & No of patients & Frequency (\%) & No of patients & & \\
\hline \multicolumn{7}{|c|}{ Thoughts (recurrent thoughts of death) } \\
\hline Baseline & $48(46.6)$ & 103 & $50(47.6)$ & 105 & \multirow{4}{*}{1.030 (0.97 to 1.10$) ; 0.34$} & \multirow{4}{*}{0.867 (0.38 to 1.98$) ; 0.74$} \\
\hline 6 weeks & $23(23.5)$ & 98 & $17(17.3)$ & 98 & & \\
\hline 12 weeks & $17(17.0)$ & 100 & $19(18.8)$ & 101 & & \\
\hline 28 weeks & $11(11.7)$ & 94 & $15(15.3)$ & 98 & & \\
\hline \multicolumn{7}{|c|}{ Ideation (often thinks of suicide and has thought of specific method) } \\
\hline Baseline & $44(42.7)$ & 103 & $40(38.1)$ & 105 & \multirow{4}{*}{1.052 (0.99 to 1.12$) ; 0.13$} & \multirow{4}{*}{0.908 (0.39 to 2.11$) ; 0.82$} \\
\hline 6 weeks & $18(18.4)$ & 98 & $10(10.2)$ & 98 & & \\
\hline 12 weeks & $13(13.0)$ & 100 & $16(15.8)$ & 101 & & \\
\hline 28 weeks & $9(9.6)$ & 94 & $13(13.3)$ & 98 & & \\
\hline \multicolumn{7}{|c|}{ Acts (has attempted suicide with definite suicidal intent) } \\
\hline Baseline & $21(20.4)$ & 103 & $13(12.4)$ & 105 & \multirow{4}{*}{1.023 (0.95 to 1.10$) ; 0.54$} & \multirow{4}{*}{0.856 (0.38 to 1.94$) ; 0.71$} \\
\hline 6 weeks & $9(9.2)$ & 98 & $5(5.1)$ & 98 & & \\
\hline 12 weeks & $8(8.0)$ & 100 & $7(6.9)$ & 101 & & \\
\hline 28 weeks & $6(6.4)$ & 94 & $7(7.1)$ & 98 & & \\
\hline \multicolumn{7}{|c|}{ Medical lethality (considerable harm from attempted suicide such as brief unconsciousness) } \\
\hline Baseline & $4(3.9)$ & 103 & $3(2.9)$ & 105 & \multirow{4}{*}{0.955 (0.84 to 1.08$) ; 0.47$} & \multirow{4}{*}{$2.446(0.67$ to 8.92$) ; 0.18$} \\
\hline 6 weeks & $1(1.0)$ & 98 & $2(2.0)$ & 98 & & \\
\hline 12 weeks & $1(1.0)$ & 100 & $3(3.0)$ & 101 & & \\
\hline 28 weeks & $2(2.1)$ & 94 & $3(3.1)$ & 98 & & \\
\hline \multicolumn{7}{|c|}{ Self harm (non-suicidal) $\ddagger$} \\
\hline Baseline & $23(22.3)$ & 103 & $30(28.6)$ & 105 & \multirow{4}{*}{0.939 (0.88 to 1.01$) ; 0.070$} & \multirow{4}{*}{2.681 (1.15 to 6.26$) ; 0.023$} \\
\hline 6 weeks & $5(5.1)$ & 98 & $18(18.4)$ & 98 & & \\
\hline 12 weeks & $11(11.0)$ & 100 & $15(14.9)$ & 101 & & \\
\hline 28 weeks & $9(9.6)$ & 94 & $12(12.2)$ & 98 & & \\
\hline
\end{tabular}

*Adjusted for time, sex, age, site, behavioural disorder, children's global assessment scale, and baseline value of outcome measure.

$\ddagger$ Frequent ( $\geq 4$ times/year) or has caused serious injury to self (such as burn with scarring, broken bone). 


\section{WHAT IS ALREADY KNOWN ON THIS TOPIC}

There is no clear cut optimal treatment for major depression in adolescents

Treatment can be effective in the short term, though use of selective serotonin reuptake inhibitors (SSRIs) might be associated with suicidality

NICE guidelines advocate specific psychological therapy, such as cognitive behaviour therapy, in conjunction with SSRIs

\section{WHAT THIS STUDY ADDS}

For referred patients in a specialist service setting the addition of CBT to treatment with an SSRI and routine specialist clinical care does not confer any additional benefit in clinical outcomes
2004. (Clinical guideline 23.) www.nice.org.uk/pdf/ CG023quickreferenceguide.pdf.

6 March J, Silva S, Petrycki S, Curry J, Wells K, Fairbank J, et al. Fluoxetine, cognitive behaviour therapy and their combination for adolescents with depression: treatment for adolescents with depression study (TADS) randomized controlled trial. JAMA 2004;292:807-20.

7 Clarke G, Debar L, Lynch F, Powell J, Gale J, O'Connor E, et al. A randomized effectiveness trial of brief cognitive-behavioral therapy for depressed adolescents receiving antidepressant medication. J Am Acad Child Adolesc Psychiatry 2005;44:888-98.

8 Melvin GA, Tonge BJ, King NJ, Heyne D, Gordon MS, Klimkeit ED. A comparison of cognitive-behavioural therapy, sertraline, and their combination for adolescent depression. J Am Acad Child Adolesc Psychiatry 2006;45:1151-61.

9 Birmaher B, Brent DA, Kolko D, Baugher M, Bridge J, Holder D, et al. Clinical outcome after short-term psychotherapy for adolescents with major depressive disorder. Arch Gen Psychiatry 2000;57:29-36.

10 Harrington RC, Whittaker J, Shoebridge P, Campbell F. Systematic review of efficacy of cognitive behaviour therapies in childhood and adolescent depressive disorder. BMJ 1998;316:1559-63.

11 American Psychiatric Association. Diagnostic and statistical manual for mental and behavioural disorders. Washington, DC: American Psychiatric Association, 1994.

12 Gowers SG, Harrington RC, Whitton A, Lelliott P, Beevor A, Wing J, et al. Brief scale for measuring the outcomes of emotional and behavioural disorders in children. Health of the Nation outcome scales for children and adolescents (HoNOSCA). Br J Psychiatry 1999;174:413-6.

13 Vallis T, Shaw B, Dobson K. The cognitive therapy scale: psychometric properties. J Consult Clin Psychol 1986;54:381-5.

Contributors: IG was chief investigator, guarantor, and grant holder responsible for final report and scientific papers. SBr was responsible for assessments over the trial period and final approval. BB was responsible for cost sensitivity analysis, drafting, revising, and final approval. SBy was responsible for health economics strategy, data analysis, drafting, revision, and final approval. BD and PW were responsible for ascertainment of patients, treatment, drafting, revision, and final approval. CF was responsible for assessments over the trial period, revising, and final approval. RK was responsible for drafting, revision, and final approval. AL was responsible for ascertainment of patients, treatment, and final approval. CR was responsible for trial methodology, sample size and data analysis, drafting, revision, and final approval. JR was responsible for assessments over the trial period and final approval. LW was responsible for revising and final approval. RH was chief investigator and grant holder responsible for original protocol.

Funding: NHS Health Technology Assessment (HTA) Programme, Central Manchester and Manchester Children's University Hospitals NHS Trust, and the Cambridge and Peterborough Mental Health Trust. The views and opinions expressed therein are those of the authors and do not necessarily reflect those of the Department of Health.

Competing interests: $\mathrm{BD}$ has been reimbursed for attending educational meetings sponsored by Lilly.

Ethical approval: Multi-centre research ethics committee and all relevant local research ethics committees.

1 Dunn V, Goodyer IM. Longitudinal investigation into childhood- and adolescence-onset depression: psychiatric outcome in early adulthood. BrJ Psychiatry 2006;188:216-22.

2 Fombonne E, Wostear G, Cooper V, Harrington R, Rutter M. The Maudsley long-term follow-up of child and adolescent depression. 1. Psychiatric outcomes in adulthood. Br J Psychiatry 2001;179:210-7.

3 Whittington CJ, Kendall T, Fonagy P, Cottrell D, Cotgrove A, Boddington E. Selective serotonin reuptake inhibitors in childhood depression: systematic review of published versus unpublished data. Lancet 2004;363:1341-5.

4 Dubicka B, Hadley S, Roberts C. Suicidal behaviour in youths with depression treated with new-generation antidepressants-metaanalysis. BrJ Psychiatry 2006;189:393-8.

5 National Collaborating Centre for Mental Health. Quick reference guide. Depression: management of depression in primary and secondary care. London: National Institute of Clinical Excellence,
14 Kaufman J, Birmaher B, Brent D, Rao U, Flynn C, Moreci P, et al. Schedule for affective disorders and schizophrenia for school-age and validity data. J Am Acad Child Adolesc Psychiatry 1997;36:980-8

15 Bilenberg N. Health of the nation outcome scales for children and adolescents (HoNOSCA) -results of a Danish field trial. Eur Child Adolesc Psychiatry 2003;12:298-302.

16 Wood A, Kroll L, Moore A, Harrington RC. Properties of the mood and feelings questionnaire: a research note. J Child Adolesc Psycho Psychiatry 1995;36:298-302.

17 Poznanski EO, Grossman JA, Buchsbaum Y, Banegas M, Freeman L, Gibbons R. Preliminary studies of the reliability and validity of the children's depression rating scale. J Am Acad Child Psychiatry 1984;23:191-7.

18 Dyrborg J, Larsen FW, Nielsen S, Byman J, Nielsen BB, Gautre-Delay F. The children's global assessment scale (CGAS) and global assessment of psychosocial disability (GAPD) in clinical practicesubstance and reliability as judged by intraclass correlations. Eur Child Adolesc Psychiatry 2000;9:195-201.

19 Guy W. ECDEU assessment manual for psychopharmacology. Washington, DC: US Government Printing Office, 1976.

20 Byford S, Harrington R, Torgerson D, Kerfoot M, Dyer E, Harrington V, et al. Cost-effectiveness analysis of a home-based social work intervention for children and adolescents who have deliberately poisoned themselves. Results of a randomised controlled trial. $\mathrm{Br}$ J Psychiatry 1999;174:56-62.

21 Diggle PJ, Liang KY, Zeger SL. Analysis of longitudinal data. Oxford: Oxford Scientific Publications, 1994.

22 Crits-Christoph P, Mintz J. Implications of therapist effects for the design and analysis of comparative studies of psychotherapies. J Consult Clin Psychol 1991;59:20-6.

23 Roberts C. The implications of variation in outcome between health professionals for the design and analysis of randomized controlled trials. Stat Med 1999;18:2605-15.

24 Curry J, Rohde P, Simons A, Silva S, Vitiello B, Kratochvil C, et al. Predictors and moderators of acute outcome in the treatment for adolescents with depression study (TADS). J Am Acad Child Adolesc Psychiatry 2006;45:1427-39.

Accepted: 1 May 2007 children-present and lifetime version (K-SADS-PL): initial reliability 